\title{
Sustainable Rural Development through Union Digital Center: The Citizen Empowerment Perspective
}

\author{
Md. Rakibul Hoque \\ University of Dhaka \\ rakibul@du.ac.bd
}

\author{
Golam Sorwar \\ Southern Cross University \\ golam.sorwar@scu.edu.au
}

\author{
Md. Uzir Hossain Uzir \\ Putra Business School \\ mduzir.phd_mkt18@grad.putrabs.edu.my
}

\begin{abstract}
Sustainable development depends on the empowerment of the vast portion of rural people. Bangladesh Government has taken initiatives to empower the disadvantaged people (i.e., elderly, poor and minority) through digitalization programs, e.g., union digital centers (UDCs). This study aimed to investigate the influential factors on the empowerment process by adopting the individual and collective empowerment dimensions. A total of 400 rural people were selected with a judgmental sampling process and provided a structured questionnaire. Data were analyzed by using SPSS for descriptive analysis and CBSEM using AMOS for effect assessment. Individual empowerment and collective empowerment have significant impacts on sustainable development. It is argued that for sustainable development and reaching development benefits to every house, rural people must be empowered. The findings will contribute to the body of knowledge theoretically and assume policymakers insights to focus on rural people's development with the nation. Future researchers can add other social factors.

Keywords: Union Digital Center, Social Inclusion, Empowerment, Sustainable Development.
\end{abstract}

\section{Introduction}

Rural development is a prerequisite for overall growth in any country, especially in developing countries [1]. Urban people are inherently more empowered, and all power and development policy sources are formulated and structured in urban areas. Economic and infrastructural development are mostly available in urban areas worldwide [2]. However, economic development and economic base are highly dependent on the sustainable development of rural areas.

Sustainable development is a continuous development process that could meet the needs of the wellbeing of present and future generations [3]. It entails innovative and community actions at the grass-root level to bridge the divide among people and bring all people to the mainstream of development [4]. Rural people's empowerment builds rural community capacity and disseminates power among people in their areas [5]. Power and powerlessness are viewed as assets and poverty of a community respectively [6]. Thus, rural peoples' empowerment is the process of reducing social inequality (e.g., through knowledge, property, information and money distribution) among disadvantaged people (i.e., elderly, poor and minority) to overcome their poverty and contribute to strengthening rural socio-economic wellbeing.

Bangladesh government has taken initiatives to facilitate access to information and increase digital service use by establishing Union Digital Centres (UDCs) in the lowest administrative layer (called a union) across the country. It is reported that the provision of digital services (e.g., access to information and e-governance services) from UDCs empowers rural citizens [7, 8]. Consequently, the UDCs are profoundly working in sustainable development through individual and community empowerment through the digitalization of government services.

UDC program primarily aims for development by empowering the people in rural areas where $37 \%$ are illiterate [9]. UDCs provide cost-effective digital services for rural people [10]. UDC-mediated services like easy access to information, distribution of knowledge, and e-governance are today important for ensuring the benefits of Digital Bangladesh vision [7]. Besides, the UDC program aims to reduce social inequality by facilitating the participation in using information technology by the poor, marginalized and disadvantaged people.

However, in the context of technology intervention, it is unknown whether the individual and collective empowerment factors (i.e., gender equality and knowledge diffusion) resulted from the UDC program significantly affect sustainable development in Bangladesh. In this regard, no research has been 
conducted yet, especially using a conceptual model that can explain and prove the contribution of the UDC program to empowerment and sustainable development in Bangladesh. Therefore, this study aimed to find the factors resulting from UDC services and how these factors affect the empowerment and sustainable development of rural people. For this, the study surveyed the disadvantaged rural residents who commonly face hindrance in using IT and is significant for addressing social inequality in terms of the access to IT by disadvantaged rural people.

\section{Literature Review}

Empowerment means increasing the degree of independence and self-determination of individuals for accomplishing what they want and need. However, individuals must acquire the required knowledge and skills to make them highly potential for acting on their authority and way [11]. Empowerment can also ensure freedom as people seek in their personal lives, social lives, and political lives [12] and be achieved not only at the individual level but also at the community level. Community empowerment is the mechanism of enhancing collective control regarding consequences relevant to their stakeholders and others in a broader community. Empowerment can extend to several communities [11, 13] (e.g., a low-income neighborhood); a subculture which shares similar experiences or beliefs and values (e.g., minority groups); or an organization in which the workforce ties together (e.g., factory workers).

To confirm empowerment in community and rural areas, paying close attention to specific social, demographic, economic, and technological aspects is essential. These aspects are, but not restricted to: (a) taking an active role in the process of education and decision making; (b)gaining access to information and utilization of local resources and opportunities; (c) bringing economic transformation in one's life and community; (d) developing a sense of self-efficacy; (e) feeling hope; (f) shifting attitudes and mastering critical thinking; and (g) being valued socially [14].

Overall, empowerment allows an individual or a group to build or develop something for society and the community and confirms disadvantaged people's capability to conquer their limitations and to contribute to society [15]. The concept of empowerment focuses on power distribution in society and its transformation for social changes.

Information and communication technologies (ICTs) can facilitate empowerment through potentially increasing individuals' and communities' political, social, and economic freedoms [16]. Freedom includes access to information, unimpeded access to knowledge; economic activities and occupation; a level playing field to involve in political activities, and participation in society's decision-making process. In a technology context, empowerment is designed to produce specific effects when used by practitioners in human services, community reform agents, or goals under common conditions of individual or group intervention [17]. ICTs enormously encourage the stream of information for the socially marginalized and unaware community [18].

Several previous studies have investigated how ICT empower individual and communities. For example, ICT based community empowerment was studied in the context of natural disaster response [19], safety and security in local villages [20], sustaining health behavior [21], youth empowerment [22], woman empowerment [23], farmer empowerment [24] and rural communities empowerment [25].

In the Bangladesh context, StillmanSarrica [26] have recently found that mobile phone usage has facilitated the transformation in attitudes, skills, and practices associated with rural women. On the other hand, due to a lack of infrastructure and other issues, rural people are easily subjected to the digital divide. Therefore, establishing community telecentres like UDCs plays a critical role in empowering them through innovations in their development [27].

Several studies have indicated that the UDCs contribute substantially to community and individual empowerment in Bangladesh [10, 17, 28]. Further, the study by Abedin et al. [9] reported that the UDC program empowers rural citizens in terms of using digital services. However, none of the current studies have quantitatively tested the disadvantaged rural people's perception of how the UDC services influence their individual and collective empowerment, thereby influencing sustainable development. Therefore, this study aimed to fill the above gap and provide information to understand the impact of UDCs on sustainable development.

\section{Theoretical Framework}

Empowerment and sustainable development are closely associated with each other [29]. SianiparYudoko [30] theorized that empowerment with appropriate technology would ensure sustainable development. Therefore, the following conceptual framework (Figure 1) was proposed to investigate factors induced by UDC services influencing individual and collective empowerment in rural areas, influencing sustainable development. 


\subsection{Dynamic Capabilities Theory}

Dynamic capabilities theory is widely used to explain the capacity of an organization. Teece et al. [31] defined this theoretical concept as "the firm's ability to integrate, build, and reconfigure internal and external competencies to address rapidly changing environments". This theory is used in the plural form to explain the capacity of a firm to react or respond adequately, and timely to external changes requires a combination of multiple capacities or strengths. In this study, the empowerment of disadvantaged people (old, poor, and minority) in society is the basis of social development.

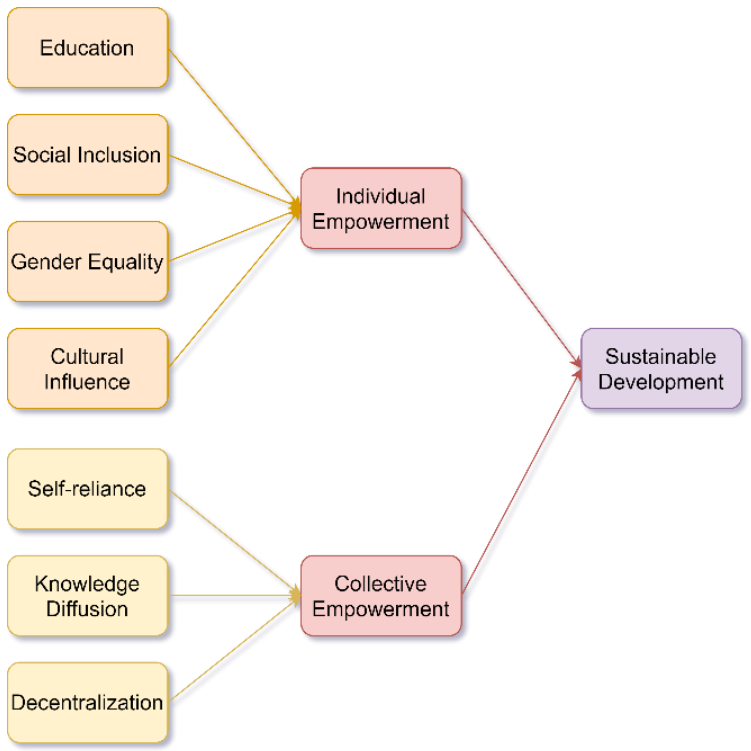

Figure 1. Proposed conceptual model based on Dynamic Capabilities Theory

\subsection{Individual Empowerment}

Individual empowerment is defined as an individual ability to make personal life decisions by accessing information. It also refers to realizing the person's capability and strength to perform daily activities in real-life situations. Rural people are much ignorant about their strength capability. Moreover, personal empowerment is confined in their lives and a critical and analytical understanding of society and politics and acquiring and improving life skills for bringing a positive change in society [32]. UDCs are the medium of developing life skills and self-trust in the rural people and widening scopes for political and social understandings.
3.2.1. Education. Access to education or education availability is the key to financial and economic success more than ever. Education, such as health education [33], entrepreneurship education [34], and ICT education [35], empowers people who can also gain freedom through learning experience and sharing knowledge. Education is essential for the empowerment of rural people; UDC plays a role in access to rural citizens' education and training, including IT training [36]. In Bangladesh, UDC is a critical factor in accessing education materials and sustainable development. Based on the above discussion, the following hypothesis was proposed:

H1. Education positively influences the individual empowerment of rural citizens.

3.2.2. Social Inclusion. Social inclusion is a muchexpected issue in sustainable development [37]. "Social capital" was described as a combination of social networks and shared confidence and reciprocity expectations that build a favorable environment for civic engagement [38]. Social inclusion is directly related and linked with social development [39]. It is a vital instrument to overcome the systematic obstacles and develop social bondage, which assists the disadvantaged part of the society, mostly the rural, to gain development opportunities. It can enhance their wellbeing and control their lives. Social inclusion can be confirmed in some ways, including them in local and traditional subculture and government; acceptable practices enable an environment in media and communication to express their voice and indigenous leadership through the UDCs. Thus, we proposed the following hypothesis:

H2. Social Inclusion positively influences the individual empowerment of rural citizens.

3.2.3. Gender Equality. Gender equality ensures an opportunity for a female to contribute to the productivity and economy of their families, communities, and society equally as their counterparts [40]. However, social structure and superstitions have broken this cohesion to some extent. Like a male, a female has a similar and, in some cases, a higher capacity to contribute to society [41, 42]. UDCs are structured and formulated to facilitate women's involvement in society and unleash them to participate equally in education, social activities and job sectors. UDC entertains women's education and training and offers financial assistance to employ themselves in entrepreneurial activities. UDC is designed and developed to ensure equity in society by eradicating gender discrimination. Therefore, we proposed the following hypothesis:

H3. Gender Equality positively influences the individual empowerment of rural citizens. 
3.2.4. Cultural Influence. Culture is a state of shared values, norms, and etiquettes among the people living in a community and/or group or society [43, 44]. Since the ancient period, culture has been practiced and nurtured among like-minded people, shaping and controlling human behaviour. Culture defines the ethics in society, guiding the rightness and wrongness in action. It also describes the social structure, economic framework and livelihood [45]. Culture can influence empowerment and community development [45]. UDC cultivates standard practices, customs, and rituals and facilitates upholding social culture. Thus, we proposed the following hypothesis:

H4. Cultural Influence positively influences the individual empowerment of rural citizens.

\subsection{Collective Empowerment}

Collective empowerment is of two formsorganizational and community empowerment [46]. An organization is a demographic spectrum of various people working in various activities to achieve a common goal. At the community level, it is generated by being empowered and helping others in empowering [25]. An ideal organization facilitates its employee to earn individual growth in financial and non-financial aspects and access organizational decision-making activities. Petrič and Petrovčič [47] illustrated that many studies were based on the theoretical frameworks of collective and individual empowerment in online communities.

3.3.1. Self-reliance. Self-reliance helps people exert more control over their lives, which helps in the selfempowerment element of development [48, 49]. If people could access and use information efficiently, they would be more self-reliant [50] and self-dependent [51] in their decision-making process and social activities contributing to society. As a result, we proposed the following hypothesis:

H5. Self-reliance positively influences collective empowerment.

3.3.2. Knowledge Diffusion. In economics, knowledge is defined as a product, and technological knowledge is new product development [52]. For the creation and distribution of knowledge, its diffusion path is crucial within the imaginative handle. Knowledge diffusion among people can be in different ways. For instance, by sharing innovative business ideas, entrepreneurs can diffuse knowledge [53]. The more experience someone has, the more power s/he occupies. 'Knowledge is power' becomes a motto of the UDCs where both males and females can access information and acquire and share knowledge among their society (e.g., dissemination of agricultural knowledge). In this way, they could overcome the learning barriers they face in rural areas [54]. Knowledge distribution ensures the social benefits among them. Therefore, we proposed the following hypothesis:

H6. Knowledge Diffusion positively influences the collective empowerment of rural citizens.

3.3.3. Decentralization. Decentralization is seen to increase efficiency, greater equity and government responsiveness to citizens [55]. It helps the government reach the welfare of their plan to every corner of the nation for the population's overall growth. The decentralization process helps to improve and dispatch facilities to rural levels [56]. A level playing social structure ensures community people improve their capacity for collective action. This collective and aggregated effort confirm a significant output, including prompting new businesses, better life, and social inclusion and equality [57].

In Bangladesh, the union council is the lowest administrative layer of the government. Keeping the importance of decentralization in mind, developing countries focus on local development policy [58]. The government initiates bringing rural people into the decision-making process to attain multi-facet objectives by confirming public participation, social, financial strength, dispersion of natural resources and management skills. Consequently, sustainable development could be achieved at every level of the country and society [59]. The expected benefits of decentralization include greater access to decisionmakers, a higher level of participation by various social groups in decision-making, and accountability of decision makers [60]. UDC has the option to bring a significant number of people into this stream [58]. Therefore, the following hypothesis was postulated:

H7. Decentralization positively influences the collective empowerment of rural citizens.

\subsection{Sustainable Development}

Individual empowerment relates to constructs, such as self-efficacy and personal competence [61]. A community empowered with individual and organizational effort and expertise can nourish and nurture the skills of rural people and utilize local resources collectively for the betterment of the society and people [62]. This collective participation and contribution empower the society individually and collectively. It has been suggested that to ensure the UDC's financial sustainability and prevent the dropouts of entrepreneurs, there is a need for sustainable income that can cling them to business and thus help with sustainability [7]. This is how UDCs bring a significant 
change in society, even with a little effort. Gradually, UDCs empower rural people, individually and collectively, by providing them easy access to information about government services, agriculture, farming, education, health and law and supporting rural entrepreneurs for sustainability [63]. Therefore, we proposed the following hypothesizes:

H8. Individual empowerment positively influences sustainable development.

H9. Collective empowerment positively influences sustainable development

\section{Methodology}

Individuals using services from UDC are the target population, primarily rural citizens. The current research used a judgment sampling procedure to select the sample. Data was collected from nine unions (lowest administrative layer) where UDCs exist. A sample size of 400 consisted of the disadvantaged rural residents who used UDCs services at least twice. About $68 \%$ of the respondents (272) were above 60 years old. Nearly $75 \%$ of the respondents (300) were poor. Also, $14 \%$ of the respondents (56) belonged to minority communities. For quantitative data collection, ethical informed consent was sought before their participation in the survey. Also, the privacy policy was briefed to them before participation.

A structured questionnaire was developed for data collection to measure the UDC's effect on rural people's empowerment. The questionnaire consisted of two parts: demographic information and the measurement items about UDC services factors. The questions for the items were adopted from previous studies. For instance, the items for empowerment were selected from the Integrated Questionnaire for the Measurement of Social Capital (IQ-MSC) [64]. A 5-point Likert scale was used for measurement.

The collected data were edited, processed, and transformed using the SPSS. The data analysis was performed at different levels. Descriptive analysis was conducted to analyze the demographic data to understand the sample characteristics, such as frequency distribution. Structural Equation Modelling was used to test the hypothesized relationships that guided the present study's core theoretical formulation and helped test-data-model-fit [65].

\section{Findings}

\subsection{Demographic Information}

About $72 \%$ of males and $28 \%$ of females participated in this study. Riverside areas are deprived of education, where $38 \%$ of respondents did not know how to read and write, and only $3 \%$ had post-graduation. Agriculture was the primary source of their livelihood. People were engaged in various occupations such as farming, government service, self-employed, grocery shops, and students. About $75 \%$ of people earn less than BDT10,000.

The primary online services provided by the UDC include birth registration, NID, land mutation, passport registration, utility bill payment, agriculture and farming information, character certificate, computer and IT training, immigrant registration, driving license, general and life insurance, telemedicine, public tender, legal assistance, e-ticketing, online visa processing, computer printing, and net browsing, job application, agent banking, clearing remittance and so on. Among them, $44 \%$ of people came to avail of birth certificates and $10 \%$ for NID. About $37 \%$ of the respondents praised the quality of UDC services. The satisfaction measurement regarding UDC services shows that $14 \%$ of respondents were very satisfied, and $60 \%$ were satisfied. Then, while $10 \%$ of the respondents were neutral, only $2 \%$ were very dissatisfied, and $14 \%$ were dissatisfied.

Table 1 shows that composite reliability (CR) and factor loading were above 0.70 and 0.50 [66]. The average variance extracted (AVE) of convergent validity was above 0.5 , which is statistically valid [67]. Moreover, the CR ranges are greater than AVE. It is found that AVE is greater than both maximum shared variance (MSV) and average shared variance (ASV) for discriminant validity.

The comparative fit index (CFI) assumes that all latent variables are unrelated and compares the sample covariance matrix with this null model (Table 2). These statistic values range from 0.0 to 1.0 , with values closer to 1.0, indicating good data-model-fit. The present study found that CFI was 0.974, which is acceptable. Root Mean Square Error of Approximation (RMSEA) explains the model's badness with a range from 0 to 0.1 . The current study found RMSEA 0.079, which is acceptable.

Table 3 shows that education $(\beta=0.850, \mathrm{p}<0.001)$ and gender equality $(\beta=0.863, \mathrm{p}<0.001)$ had positive and significant effect on individual empowerment whereas social inclusion $(\beta=0.067, p=0.141)$ and cultural influence $(\beta=0.198, p=0.616)$ had no significant effect on this empowerment. In the case of collective empowerment, self-reliance $\beta=0.253$, = 0.004 ), knowledge diffusion $\beta=0.447, \mathrm{p}<0.001$ ), and decentralization $\beta=0.385, \mathrm{p}<0.001$ ) had positive and significant effect on it. Moreover, individual empowerment $(\beta=0.162, \mathrm{p}=0.010)$ and collective empowerment $(\beta=0.598, p<0.001)$ significant affected the sustainable development. Thus, seven hypotheses 
such as $\mathrm{H} 1, \mathrm{H} 3, \mathrm{H} 5, \mathrm{H} 6, \mathrm{H} 7, \mathrm{H} 8$, and $\mathrm{H} 9$ were accepted and two hypotheses (H2 and $\mathrm{H} 4)$ were rejected in this model.

Table 1. Construct validity and reliability

\begin{tabular}{lccccccc}
\hline \multicolumn{1}{c}{ Factor } & $\boldsymbol{\alpha}$ & CR & AVE & \multicolumn{3}{c}{ Loadings } \\
\hline Education & & & & Item 1 & Item 2 & Item 3 & Item 4 \\
Social Inclusion & .961 & .964 & .900 & .927 & .946 & .973 & \\
Gender Equality & .978 & .977 & .915 & .951 & .956 & .957 & .962 \\
Culture Issue & .990 & .980 & .943 & .967 & .988 & .958 & \\
Self-reliance & .987 & .971 & .894 & .983 & .977 & .909 & .911 \\
Knowledge Diffusion & .911 & .990 & .972 & .874 & .912 & .896 & \\
Decentralization & .893 & .968 & .910 & .982 & .987 & .988 & \\
Individual Empowerment & .932 & .978 & .900 & .955 & .963 & .943 & .954 \\
Collective Empowerment & & .923 & .799 & .968 & .993 & .911 & .970 \\
Sustainable Development & & .986 & .947 & .998 & .951 & .869 & \\
\hline
\end{tabular}

Table 2. Data-model-fit

\begin{tabular}{ccc}
\hline CFI & RMR & RMSEA \\
\hline .974 & .062 & .079 \\
\hline
\end{tabular}

\section{Discussion}

The results obtained from the structural equation model show that two estimated path coefficients of social inclusion and cultural influence do not support the hypotheses. The other seven hypotheses were supported accordingly. Overall, the conceptual model can explain the factors influencing sustainable development and variance in sustainable development. It is found that education and gender equality are vital factors for individual empowerment for rural people. These findings were consistent with previous studies conducted by Jayesh and Peravurani [68] and OedlWieser [69].

Table 3. Path co-efficient of empowerment induced to sustainable development model after structural modeling

\begin{tabular}{|c|c|c|c|c|}
\hline Parameter Estimates & $\boldsymbol{\beta}$ & S.E. & $P$ value & Comment \\
\hline Individual Empowerment $\leftarrow$ Education & .850 & .081 & .000 & Accepted \\
\hline Individual Empowerment $\leftarrow$ Social Inclusion & .067 & .096 & .141 & Rejected \\
\hline Individual Empowerment $\leftarrow$ Gender Equality & .863 & .101 & .000 & Accepted \\
\hline Individual Empowerment $\leftarrow$ Cultural Influence & .098 & .056 & 616 & Rejected \\
\hline Collective Empowerment $\leftarrow$ Self-reliance & .253 & .062 & .004 & Accepted \\
\hline Collective Empowerment $\leftarrow$ Knowledge Diffusion & .447 & .062 & .000 & Accepted \\
\hline Collective Empowerment $\leftarrow$ Decentralization & .385 & .068 & .000 & Accepted \\
\hline Sustainable Development $\leftarrow$ Individual Empowerment & .162 & .062 & .009 & Accepted \\
\hline Sustainable Development $\leftarrow$ Collective Empowerment & .598 & .034 & .000 & Accepted \\
\hline
\end{tabular}

Self-reliance, knowledge diffusion, and decentralization of power were also found vital factors for collective empowerment. This finding conforms with the studies by Tantoh and McKay [70], BuchoriPramitasari [71], and Ahmad and Talib [58]. Moreover, the findings on individual and collective empowerment about sustainable development align with the study findings by KaponderaPanteli [25] and AbosedeGaniyu [72].
Although the previous studies indicated that social inclusion [37] and cultural [45] effects are important issues in society, the current study shows these two factors were not identified as significant factors by the rural people in empowering them. A primary reason for such findings could be a lack of minimum resources and necessary knowledge to avail services and benefits from the UDC centers. It is essential to mention that $38 \%$ of the respondents living near the riverine areas and below 
the poverty line had no literacy. The contribution made by the UDC program to individual and collective empowerment on sustainable development is statistically significant.

The government makes efforts to empower the rural community, ensuring the country's overall growth. In this regard, the UDCs attempt to disperse awareness of being learned and cultivating education. This awareness influences all walks of life, from children to older people. Multi-prone services provided by the UDCs were beneficial for them, their family members, and their locality. UDC's service brought a positive change in their lives [73]. Though NID and birth certificates are frequently searched services, online job applications, driving licenses, and VISA processing are also very demanding for local people. Before UDCs, people had to rush to the district level for these services, which were time-consuming, costly and against their will. Therefore, the demand for utilizing UDC services has increased rapidly and widely over the years.

\section{Implications}

This study has several significant implications. Firstly, the present study found that ICT-based education significantly influences individual development. Rural people need the education to involve themselves in development activities. Furthermore, this study has contributed by investigating gender equality in individual empowerment like woman empowerment. As women empowerment and economic development are interrelated, an increase in women's economic involvement (e.g., entrepreneurship) by the UDC program has contributed to economic development. This study also implies that women's involvement and participation by increasing gender equality enhance sustainable rural development [74].

Besides, UDC is positioning a knowledge-based knowledge served-institution, allowing easy and quick access to information and services for common people [75]. It has great potentiality to reduce time visits and cost in service delivery compared to alternative providers. Previous studies found that the UDC program also facilitates the self-reliance process by minimizing hassles, intermediary free services, reduced corruption, and greater transparency [76]. UDC centers are shared and collective access points for rural people where the entrepreneur or service providers are ready to assist rural people in accessing government, private, and commercial information and services [7]. According to the study, knowledge sharing among people living in rural areas significantly impacts collective empowerment. However, as per Khatun [77], it is important to address the challenges such as slow internet speed, inadequate manpower, and load shedding in
UDCs that sometimes act as barriers in obtaining services. The study by AbedinFerdaus [9] also identified that cost and lack of awareness are significant barriers to providing effective services by UDCs, hindering the empowerment process.

This study also found that sustainable development is influenced by the individual and collective empowerment of rural people, supported by previous studies [78]. In Bangladesh, rural people comprise 62.59 percent of the total population [79]. Out of 2.6 million unemployed people, 1.82 million live in rural areas [80]. Therefore, it would be impractical for any development planning to be successful without integrating large-scale ICT programs like UDC. Moreover, the objective of mass empowerment and sustainable development would not be adequately fulfilled without understanding the perceptions of ICT program beneficiaries (general rural people). The rural people must avail of the service conveniently and maximally to develop and utilize the facilities. In this regard, UDCs play vital roles in educating and empowering rural people.

From the theoretical perspective, this finding added a significant contribution to dynamic capabilities theory. The primary assumption of this theory explains the improving and developing the existing capability of an organization or society to comply with the changing environments. Similarly, the finding of the study indicated that for sustainable development of society, collective and individual efforts are prerequisite. Poor and untapped people of Bangladesh should be given the authority to play their parts. Besides, those members of the society should be facilitated the state of art opportunities and motivated to work for the nation and society. This aspiration and the authority to perform (empowerment) enable them for their own perspective and the society.

\section{Conclusion}

The findings of the study evidence that rural people frequently avail UDCs services, which, in turn, induce empowerment factors (i.e., education, gender equality, self-reliance, knowledge diffusion, and decentralization). As a result, the authors conclude that UDC services cause disadvantaged (i.e., elderly, poor and minority) rural people's empowerment and subsequently influence sustainable development. This study especially identified that the government's largescale digital technology intervention could facilitate mass-scale rural development and sustainably. The study also found that education and gender equality in society directly influences individual empowerment. Moreover, decentralization is one of the critical factors for collective empowerment. As decentralized government activities and the diversified nature of 
planning are development-friendly, they can smoothly advance a community and society. Through ICT programs like the UDC, individual and collective empowerment can broadly be attained by the rural people. In this way, they would be able to exercise their rights and use their local resources to contribute to sustainable development.

This study is significant for statistically investigating how a countrywide ICT intervention like the UDC program could contribute to mass empowerment and sustainable development. However, a major limitation of the study is with the judgment sampling, which is cheap, efficient, and easy to conduct but lacks generalizability. Further, the study has not considered the influence of demographics factors (e.g., gender) that can also be investigated as moderating factors in future studies.

\section{References}

[1] Chambers, R., Rural development: Putting the last first. New York, NY: Routledge. 2014.

[2] Maparu, T.S. and T.N. Mazumder, "Transport infrastructure, economic development and urbanization in India (1990-2011): Is there any causal relationship?," Transportation Research Part A: Policy and Practice, 100, 2017. pp. 319-336.

[3] Griggs, D., et al., "Sustainable development goals for people and planet," Nature, 495(7441), 2013. pp. 305307.

[4] Seyfang, G. and A. Smith, "Grassroots innovations for sustainable development: Towards a new research and policy agenda," Environmental Politics, 16(4), 2007. pp. 584-603.

[5] Steiner, A.A. and J. Farmer, "Engage, participate, empower: Modelling power transfer in disadvantaged rural communities," Environment Planning C: Politics and Space, 36(1), 2018. pp. 118-138.

[6] Abiche, T.T., "Community empowerment and sustainable livelihoods: Transforming social capital into entrepreneurship in rural Southern Ethiopia," University of South Africa, Doctot of Philosphy, Pretoria, 2012 pp.

[7] Faroqi, M.G., "Financial sustainability of union digital center in Bangladesh," Journal of Developing Areas, 49(6), 2015. pp. 61-73.

[8] Hasanuzzaman, Union Digital Centre: Prioritising government's one-stop rural shop, The Daily Star, Dhaka, 2019 , https://www.thedailystar.net/opinion/economics/news/ union-digital-centre-prioritising-governments-onestop-rural-shop-1739107.

[9] Abedin, M.M., et al., "The Role of Union Digital Centres in Reducing Social Inequalities in Bangladesh," Bangladesh Journal of Public Administration, 30(1), 2021. pp. 1-16.

[10] Ullah, M.S., "ICTs, power prejudice and empowerment: Digital exclusion of the poor in rural Bangladesh," in
To the best of our knowledge, this was the first of its kind to examine quantitatively how large-scale technology intervention like the UDC program by the government could empower the rural people and contribute to sustainable development. This study explains how technology intervention could facilitate education, gender equality, self-reliance, knowledge diffusion, and decentralization, thereby facilitating the empowerment and achievement of the Sustainable Development Goals of the United Nations Development Programme.

\section{Acknowledgement}

This work was supported by research grant of Dhaka University under grant No. (85568). The authors, therefore, gratefully acknowledge the University of Dhaka for technical and financial support.

Digital inequalities in the Global South, Springer International Publishing: Switzerland. 2020.pp. 103133

[11] Sumartini, A.R. and I.A.A. Idawati, "Development of culture village through service quality analysis to customer satisfaction," International Research Journal of Management, IT \& Social Sciences, 7(3), 2020. pp. 98-103.

[12] Islam, A. and K. Tsuji, "Evaluation of usage of university websites in Bangladesh," DESIDOC Journal of Library \& Information Technology, 31(6), 2011.

[13] Umanailo, M.C.B., "Integration of Community Empowerment Models [Pengintegrasian Model Pemberdayaan Masyarakat]," Proceeding of Community Development, 2, 2019. pp. 268-277.

[14] Han, K.S., et al., "A structural model of family empowerment for families of children with special needs," Journal of Clinical Nursing, 27(5-6), 2018. pp. e833-e844.

[15] Otto, D., et al., "Can MOOCs empower people to critically think about climate change? A learning outcome based comparison of two MOOCs," Journal of Cleaner Production, 222, 2019. pp. 12-21.

[16] Bailur, S. and B.-S. Gigler, "Introduction: the potential for empowerment through ICTs," in Closing the Feedback Loop, World Bank Group: Wahsington, USA. 2014.pp. 1

[17] Ullah, M.S., "Empowerment, Asymmetrical Power Relations and Impacts of Information Technology in Rural Bangladesh," South Asia Research, 37(3), 2017. pp. 315-334.

[18] Akbar, S.U., "ICT and social transformation in rural Bangladesh," Information Technology in Developing Countries, 14(3), 2004. pp. 16-18.

[19] Leong, S.H. and D. Kranzlmüller. A task-based ubiquitous approach to urgent computing for disaster management. in 2015 2nd International Conference on Information and Communication Technologies for Disaster Management (ICT-DM). Rennes, France: IEEE. 2015. 
[20] Pisuena, J.S. and A.M.M. Lamis, "A Community Empowerment Model using ICT for Safety and Security in a Local Village," Asia Pacific Journal of Multidisciplinary Research, 7(2), 2019.

[21] Alluhaidan, A., et al. Sustaining health behaviors through empowerment: a deductive theoretical model of behavior change based on information and communication technology (ICT). in International Conference on Persuasive Technology. Waterloo, Canada: Springer. 2018.

[22] Onwumere, A.A. and A. Adigwe, "ICT and youth empowerment in Nigeria," Journal of Public Administration and Social Welfare Research, 2(1), 2017. pp. 39-47.

[23] Adeni, S., "Information Communication Technology (ICT) and Women Empowerment for Rural Area," Jurnal InterAct, 5(2), 2016. pp. 1-15.

[24] Praditya, D., "Farmer Empowerment By ICT Community," Jurnal Penelitian Komunikasi, 19(1), 2016.

[25] Kapondera, S.K., et al. Telecentre Users as Mediators of Empowerment of Rural Communities in Malawi. in 2020 IST-Africa Conference (IST-Africa). Uganda: IEEE. 2020.

[26] Stillman, L., et al., "Sociotechnical Transformative Effects of an ICT Project in Rural Bangladesh," American Behavioral Scientist, 64(13), 2020. pp. 1871-1888.

[27] Tahir, Z., et al., "Developing smart ICT in rural communities in Malaysia through the establishment of telecenters," e-Bangi, 13(1), 2016. pp. 227-242.

[28] Rashid, A.T. and A.K. Rashid, "Rural ICT business in Bangladesh: a credible development agent?," South Asia Research, 40(1), 2020. pp. 58-74.

[29] Tabari, S., "Domination of closed Rentier networks on Tehran's urban management," Socio-Spatial Studies, 3(7), 1999. pp. 62-79.

[30] Sianipar, C.P.M., et al., "Community empowerment through appropriate technology: Sustaining the sustainable development," Procedia Environmental Sciences, 17, 2013. pp. 1007-1016.

[31] Teece, D.J., et al., "Dynamic capabilities and strategic management," Strategic Management Journal, 18(7), 1997. pp. 509-533.

[32] Chowdhury, K., Human Rights Discourse in the Post9/11 Age. Saint Paul, USA: Springer. 2019.

[33] Lin, C.-Y., et al., "Can a modified theory of planned behavior explain the effects of empowerment education for people with type 2 diabetes?," Therapeutic Advances in Endocrinology and Metabolism, 11, 2020. pp. 1-12.

[34] Santos, S.C., et al., "Entrepreneurship education in a poverty context: An empowerment perspective," Journal of Small Business Management, 57, 2019. pp. 6-32.

[35] Khan, F. and R. Ghadially, "Empowerment through ICT education, access and use: A gender analysis of Muslim youth in India," Journal of International Development, 22(5), 2010. pp. 659-673.

[36] Akther, F. Rural Community Development Strategy beyond the Access to Information: The Role of Tele-
Centers in Bangladesh. in IADIS Conference. Berlin, Germany: International Association for Development, IADIS. 2012.

[37] Raicov, M. and A. Feher, "Social inclusion, sustainable development and evolution of rural poverty in Romania," Agricultural Economics and Rural Development, 15(1), 2018. pp. 71-81.

[38] Dempsey, N., et al., "The social dimension of sustainable development: Defining urban social sustainability," Sustainable development, 19(5), 2011. pp. 289-300.

[39] Sachs, J.D., "From millennium development goals to sustainable development goals," The Lancet, 379(9832), 2012. pp. 2206-2211.

[40] Lawal, F.A., et al. Promoting Gender Equality and Women's Empowerment for Sustainable Development in Africa. in 3rd International Conference on African Development Issues. Covenant University, Ota, Nigeria. 2016.

[41] Mandal, M., et al., "A review of measures of women's empowerment and related gender constructs in family planning and maternal health program evaluations in low-and middle-income countries," BMC Pregnancy and Childbirth, 17(2), 2017. pp. 1-9.

[42] Abukhait, R.M., et al., "Empowerment, knowledge sharing and innovative behaviours: Exploring gender differences," International Journal of Innovation Management, 23(01), 2019. pp. 1950006.

[43] Thompson, M., et al., Cultural Theory. New York: Routledge. 2018, 296.

[44] Delango, M.W., "The Impact of Cultural Practices on Women Empowerment: The Case of Offa Woreda, Wolaita Zone, Southern Ethiopia," Social Sciences, 8(4), 2019. pp. 175-184.

[45] Díaz-Puente, J.M., et al., "Empowering communities through evaluation: some lessons from rural Spain," Community Development Journal, 44(1), 2009. pp. 5367.

[46] Stoeffler, S.W., "Community Empowerment," in Handbook of Community Movements and Local Organizations in the 21st Century, Springer: Cham, Switzerland. 2018.pp. 265-280

[47] Petrič, G. and A. Petrovčič, "Individual and collective empowerment in online communities: the mediating role of communicative interaction in web forums," The Information Society, 30(3), 2014. pp. 184-199.

[48] Ekesionye, E. and A. Okolo, "Women empowerment and participation in economic activities: Indispensable tools for self-reliance and development of Nigerian society," Educational Research and Reviews, 7(1), 2012. pp. 1018.

[49] Alonge, H.O., et al., "Women empowerment for selfreliance: Educational management strategies in Nigeria Case," Journal of Educational Social Research, 4(1), 2014. pp. 517.

[50] Chapin III, F.S., et al., "Community-empowered adaptation for self-reliance," Current Opinion in Environmental Sustainability, 19, 2016. pp. 67-75.

[51] Bhuyan, D., Empowerment of Indian women: A challenge of 21st century, Orissa Review, Academia, 60-63, January 2006, 2006 
[52] Klarl, T., Knowledge diffusion and knowledge transfer: two sides of the medal, ZEW-Centre for European Economic Research Discussion Paper, 2009,

[53] Ratten, V., "Entrepreneurship as Empowerment: Knowledge spillovers and entrepreneurial ecosystems," in Entrepreneurship as Empowerment: Knowledge Spillovers and Entrepreneurial Ecosystems, Emerald Publishing Limited: Bingley. 2020

[54] Aziz, A., "Digital inclusion challenges in Bangladesh: The case of the National ICT Policy," Contemporary South Asia, 28(3), 2020. pp. 304-319.

[55] Fakhruddin, I., "Decentralization and community empowerment: a discourse analysis of local forestry regulations in Indonesia," University of Melbourne, Doctor of Philosophy, Melbourne, 2016 pp.

[56] Roche, B., New directions in Community-based Research. Toronto: Wellesley Institute. 2010.

[57] Gutberlet, J., "Solidarity economy and recycling co-ops in Sao Paulo: micro-credit to alleviate poverty," Development in Practice, 19(6), 2009. pp. 737-751.

[58] Ahmad, M.S. and N.B.A. Talib, "Empowering local communities: decentralization, empowerment and community driven development," Quality \& Quantity, 49(2), 2015. pp. 827-838.

[59] Awortwi, N., "An unbreakable path? A comparative study of decentralization and local government development trajectories in Ghana and Uganda," International Review of Administrative Sciences, 77(2), 2011. pp. 347-377.

[60] Uddin, N., "Empowerment through decentralization: conceptions, contrivances and connections," Dynamics of Public Administration, 34(1), 2017. pp. 86-101.

[61] Biron, M. and P. Bamberger, "The impact of structural empowerment on individual well-being and performance: Taking agent preferences, self-efficacy and operational constraints into account," Human Relations, 63(2), 2010. pp. 163-191.

[62] Crittenden, V.L., et al., "Empowering women microentrepreneurs in emerging economies: The role of information communications technology," Journal of Business Research, 98, 2019. pp. 191-203.

[63] Hoque, M.R., "The impact of the ICT4D project on sustainable rural development using a capability approach: Evidence from Bangladesh," Technology in Society, 61, 2020. pp. 101254.

[64] Soares, M.F., et al., "Individual and collective empowerment and associated factors among Brazilian adults: a cross-sectional study," BMC Public Health, 15(1), 2015. pp. 1-11.

[65] Barrett, P., "Structural equation modelling: Adjudging model fit," Personality and Individual differences, 42(5), 2007. pp. 815-824.

[66] Cronbach, L.J., "Coefficient alpha and the internal structure of tests," psychometrika, 16(3), 1951. pp. 297-334.
[67] Bagozzi, R.P. and Y. Yi, "On the evaluation of structural equation models," Journal of the Academy of Marketing Science, 16(1), 1988. pp. 74-94.

[68] Jayesh, G.S. and T.N. Peravurani, "Inclusive Education: Empowerment for Rural Women through Education," in Women Empowerment: Challenges and Strategies, Booksclinic Publishing: Chhattishgarh, India. 2019.pp. 196-205

[69] Oedl-Wieser, T., "Gender equality: a core dimension in Rural Development Programmes in Austria?," Gender, Place and Culture, 22(5), 2015. pp. 685-699.

[70] Tantoh, H.B. and T.J. McKay, "Rural self-empowerment: The case of small water supply management in Northwest, Cameroon," GeoJournal, 85(1), 2020. pp. 159-171.

[71] Buchori, I., et al., "Adaptation to coastal flooding and inundation: Mitigations and migration pattern in Semarang City, Indonesia," Ocean and Coastal Management, 163, 2018. pp. 445-455.

[72] Abosede, A.B., et al., "Strategies for Optimizing Business Education as an Instrument of Economic Empowerment and Sustainable Development in Nigeria," Africa Journal of Technical and Vocational Education, 5(1), 2020. pp. 52-65.

[73] Hoque, M.R. and G. Sorwar. E-Governance for Rural Development: a Case Study on Union Information and Service Centre (UISC) of Bangladesh. in PACIS. Chengdu, China. 2014.

[74] Agarwal, B., "Gender equality, food security and the sustainable development goals," Current opinion in Environmental Sustainability, 34, 2018. pp. 26-32.

[75] a2i. UDC as a platform of social change: A depth Study. Access to Information, Bangladesh. Dhaka [cited 2017; 2015 Available from: https://a2i.gov.bd/.

[76] Faroqi, M.G. and N.A. Siddiquee. Impacts of telecentre on users: the experience of the Union Digital Centre in Bangladesh. in Proceedings of the 10th International Conference on Theory and Practice of Electronic Governance. New Delhi, India. 2017.

[77] Khatun, F., "Union Digital Centers (UDCs): roles, challenges and potentialities," Journal of Emerging Trends in Economics Management Sciences, 11(3), 2020. pp. 78-84.

[78] Kapondera, S.K., et al. A Framework for Understanding the Empowerment Effects of Telecentres on Rural Communities in Developing Countries. in International Conference on Social Implications of Computers in Developing Countries. Manchester, United Kingdom: Springer. 2019.

[79] Bank, W. Rural population (\% of total population) Bangladesh. [cited 2021 September 2021]; 2019.

[80] Molla, M.A.M. and W.B. Habib, 26 lakh jobless., The Daily Star, Dhaka, https://www.thedailystar.net/frontpage/26-lakhyouths-jobless-1411804. 